CLINICAL STUDY

\title{
Association of acylated ghrelin profiles with chronic inflammatory markers in overweight and obese postmenopausal women: a MONET study
}

David H St-Pierre, Jean-Philippe Bastard ${ }^{1}$, Lise Coderre ${ }^{2}$, Martin Brochu ${ }^{3}$, Antony D Karelis ${ }^{4}$, Marie-Ève Lavoie, Florin Malita, Jonathan Fontaine, Diane Mignault, Katherine Cianflone ${ }^{5}$, Pascal Imbeault ${ }^{6}$, Éric Doucet ${ }^{6}$ and Rémi Rabasa-Lhoret

Département de Nutrition, Université de Montréal, Montréal, Québec, Canada, H3T 1A8, ${ }^{1}$ Faculté de Médecine Saint-Antoine, AP-HP, Hôpital Tenon, Service de Biochimie et Hormonologie, INSERM U680, Université Pierre et Marie Curie, 75970 Paris, France, ${ }^{2}$ Département de Médecine, Université de Montréal, Montréal, Québec, Canada J1K 2R1, ${ }^{3}$ Faculté d'éducation Physique et Sport, Université de Sherbrooke, Sherbrooke, Québec, Canada H3C 3P8, ${ }^{4}$ Département de Kinanthropologie, Université du Québec à Montréal, Montréal, Québec, Canada G1V 4G5, ${ }^{5}$ Centre de Recherche Hôpital Laval, Université Laval, Laval, Québec, Canada and ${ }^{6}$ Faculty of Health Sciences, School of Human Kinetics, University of Ottawa, Ottawa, Ontario, Canada K1N 6N5

(Correspondence should be addressed to R Rabasa-Lhoret; Email: remi.rabasa-Ihoret@umontreal.ca)

\begin{abstract}
Objective: Recent reports have suggested that the existence of associations between hormonal dysregulation and chronic upregulation of inflammatory markers, which may cause obesity-related disturbances. Thus, we examined whether acylated ghrelin (AcylG) and total ghrelin (TotG) levels could be associated with the following inflammatory markers: C-reactive protein (CRP), tumor necrosis factor $\alpha$ (TNF- $\alpha$ ), and soluble TNF receptor 1 (sTNF-R1).

Design: Cross-sectional study consisting of 50 overweight and obese postmenopausal women.

Methods: AcylG and TotG levels were assessed at 0, 60, 160, 170, and $180 \mathrm{~min}$ of the euglycemic/hyperinsulinemic clamp (EHC). We evaluated insulin sensitivity, body composition, and blood lipid profiles as well as fasting concentrations of CRP, TNF- $\alpha$, and sTNF-R1.

Results: In fasting conditions, sTNF-R1 was negatively correlated with AcylG $(r=-0.48, P<0.001)$ levels. In addition, AcylG/TotG was associated negatively with sTNF-R1 $(r=-0.44, P=0.002)$ and positively with TNF- $\alpha(r=0.38, P=0.009)$ values. During the EHC, TotG (at all time points) and AcylG (at 60 and $160 \mathrm{~min}$ ) values were significantly decreased from fasting concentrations. AcylG maximal reduction and area under the curve (AUC) values were correlated to sTNF-R1 ( $r=-0.35$, $P=0.02$ and $r=-0.34, P=0.02$, respectively). Meanwhile, the AcylG/TotG AUC ratio was associated negatively with sTNF-R $1(r=-0.29, P<0.05)$ and positively with TNF- $\alpha(r=0.36$, $P=0.02$ ). Following adjustments for total adiposity, sTNF-R1 remained correlated with fasting and maximal reduction AcylG values. Similarly, AcylG/TotG ratios remained significantly correlated with sTNF-R1 and TNF- $\alpha$. Importantly, $23 \%$ of the variation in sTNF-R1 was independently predicted by fasting AcylG.

Conclusion: These results are the first to suggest that both fasting and EHC-induced AcylG profiles are correlated with fasting values of sTNF-R1, a component of the TNF- $\alpha$ system. Thus, AcylG may act, at least in part, as one mediator of chronic inflammatory activity in human obesity.
\end{abstract}

European Journal of Endocrinology 157 419-426

\section{Introduction}

Ghrelin, a gut-derived peptide (1), has been shown to be associated with insulin sensitivity (2-6). Total ghrelin (TotG) includes acylated ( $\sim 10 \%$ of TotG) and nonacylated ( $\sim 90 \%$ of TotG) ghrelin (AcylG and NAcylG respectively), two distinct forms that were previously identified in circulation $(1,7)$. The physiology of AcylG and NAcylG suggests that the existence of intimate relationships with insulin secretion/sensitivity. For instance, under euglycemic/hyperinsulinemic clamp (EHC) conditions, a model of hyperinsulinemia, TotG levels are reduced to a greater extent in normal individuals when compared with insulin resistant or diabetic subjects (8-10). Moreover, postprandial reduction of AcylG is positively associated with insulin sensitivity in children with Prader-Willi syndrome (11). Furthermore, at pharmacological concentrations, AcylG increases the degree of insulin resistance, whereas co-administration of AcylG and NAcylG 
improves insulin sensitivity $(12,13)$. Thus, AcylG and NAcylG forms may induce different physiological and/or metabolic effects.

There is growing evidence suggesting that the development of obesity-related disturbances may be closely associated with gut-derived hormonal dysregulation and chronic inflammation (14-17). There is presently conflicting information regarding the association between TotG and markers of chronic inflammation. For instance, both in vivo and in vitro studies have provided evidence that ghrelin can exert antiinflammatory effects by reducing pro-inflammatory cytokine expression $(18,19)$. In addition, TotG concentrations are negatively correlated with tumor necrosis factor $\alpha$ (TNF- $\alpha$ ) and C-reactive protein (CRP) levels in patients with chronic obstructive pulmonary diseases (20). On the other hand, TotG levels are positively associated with TNF- $\alpha$ in subjects with chronic heart failure (21). Although indications suggest that possible interactions with the TNF- $\alpha$ system discrepancies still remain regarding metabolic outcomes of the relation between ghrelin and TNF- $\alpha$. Moreover, recent evidence have suggested that the soluble TNF receptor 1 (sTNF-R1) is a better indicator of metabolic dysfunctions than TNF- $\alpha$ itself (16). Furthermore, the relationship between ghrelin and chronic inflammatory markers has not been evaluated in an exhaustively phenotyped population of sedentary overweight and obese postmenopausal women with high risks to develop metabolic disturbances. Therefore, the purpose of the present study was to investigate whether fasting levels of chronic inflammatory markers, such as CRP, TNF- $\alpha$, and sTNF-R1 are associated with a complete profile of AcylG, TotG, and AcylG/TotG values characterized before and during an $\mathrm{EHC}$ in overweight and obese postmenopausal women.

\section{Subjects and methods}

\section{Subjects}

The study population consisted of 53 non-diabetic overweight and obese postmenopausal women aged between 48 and 73 years old. Women were included in the study if they met the following criteria: 1) body mass index $>27 \mathrm{~kg} / \mathrm{m}^{2}$, 2) follicle-stimulating hormone levels $\geq 30 \mathrm{U} / \mathrm{l}, 3)$ sedentary $(<2 \mathrm{~h}$ a week of structured exercise), 4) non-smokers, 5) low to moderate alcohol consumption ( $<2$ drinks/day), 6) absence of any known inflammatory disease, and 7) no use of hormone replacement therapy within the last 3 months. On physical examination or biological testing, no participant had a history or evidence of: 1) cardiovascular diseases, peripheral vascular diseases, or stroke, 2) diabetes evaluated by a $2 \mathrm{~h} 75 \mathrm{~g}$ oral glucose tolerance test, 3) orthopedic limitations, 4) uncontrolled thyroid or pituitary diseases, 5) infection (medical questionnaire examination and complete blood count), or 6) medication that could affect cardiovascular function and/or metabolism. The study was approved by the University of Montreal ethics committee.

\section{Sequence of tests}

After reading and signing the consent form each participant was invited to the Metabolic Unit for a series of tests. After a 4-week period of weight stabilization, patients underwent a $3 \mathrm{~h}$ EHC. Body composition was determined by dual energy X-ray absorptiometry (DXA) and body fat distribution by the computed tomography (CT) technique.

\section{Euglycemic/hyperinsulinemic clamp (EHC)}

The test began at $0730 \mathrm{~h}$ after a 12-h overnight fast following the procedure described by DeFronzo et al. (22) A catheter was introduced in the antecubital vein for the infusion of $20 \%$ dextrose and insulin (Actrapid, Novo-Nordisk, Toronto, Canada). Another catheter was inserted into the other arm for blood sampling. Three fasting samples of plasma glucose and insulin were collected over $40 \mathrm{~min}$. Then, insulin was infused at the rate of $75 \mathrm{mU} / \mathrm{m}^{2}$ per min for $180 \mathrm{~min}$. Plasma glucose was measured every $10 \mathrm{~min}$ with a glucose analyzer (Beckman Instruments, Fullerton, CA, USA) and maintained at fasting level with a variable infusion rate of $20 \%$ dextrose. Glucose disposal (insulin sensitivity) was calculated as the mean rate of glucose infusion measured during the last $30 \mathrm{~min}$ of the clamp steady state and was expressed as $\mathrm{mg} / \mathrm{min}$ per $\mathrm{kg}$ of fatfree mass.

\section{Blood samples}

After an overnight fast (12 h) blood samples were collected at times $0,60,160,170$, and 180 min during the EHC. Fasting serum samples of triglyceride, high density lipoprotein (HDL-cholesterol), low density lipoprotein (LDL-cholesterol), insulin, glucose, CRP, TNF- $\alpha$, and sTNF-R 1 concentrations were analyzed at 0 min. Moreover, AcylG and TotG levels were measured at $0,60,160,170$, and $180 \mathrm{~min}$ during the EHC. Blood samples were centrifuged at $3900 \boldsymbol{g}$ for $10 \mathrm{~min}$ at $4{ }^{\circ} \mathrm{C}$ and kept at $-80^{\circ} \mathrm{C}$ until further analyses were achieved. For AcylG samples, plasma was treated with $50 \mu \mathrm{l} / \mathrm{ml} \mathrm{HCL}(1 \mathrm{M})$ and $10 \mu \mathrm{l} / \mathrm{ml}$ phenylmethylsulfonyl fluoride (57.4 mM) (Sigma-Aldrich) to prevent peptidic degradation and/or loss of the acyl group on $\mathrm{Ser}^{3}$. Plasma immunoreactive AcylG and TotG levels were measured in duplicate with a commercial RIA procedure using ${ }^{125}$ I-labeled bioactive human AcylG and TotG as tracers and a rabbit polyclonal antibody raised against full-length peptides (Linco Research, 
St-Charles, MO, USA). As indicated by the manufacturer, inter- and intra-assay percent coefficients of variation were respectively under 18 and 10\%. Blood glucose and the lipid profile were analyzed on the day of collection while insulin samples were kept at $-80{ }^{\circ} \mathrm{C}$ until they were analyzed. Analyses were done on the COBAS INTEGRA 400 (Roche Diagnostic) analyzer for total cholesterol, HDL-cholesterol, and triglycerides. Total cholesterol, HDL-cholesterol, and triglycerides were used in the Friedewald formula (23) to calculate LDL-cholesterol concentration. Insulin levels were determined by RIA (Linco Research). Serum levels of CRP were assessed by immunonephelometry on IMMAGE analyzer (Beckman-Coulter, Villepinte, France), the inter- and intra-assay variations were below 5\%. Circulating TNF- $\alpha$ and sTNF-R1 levels were measured by ELISA (R\&D Systems, Minneapolis, MN, USA), the inter- and intra-assay variations were respectively below 9 and 5\%. Homeostasis model assessment for insulin resistance (HOMA-IR) was calculated according to the formula of Matthews et al. (24).

\section{Body composition}

Body weight was measured using an electronic scale (Balances Industrielles, Montreal, Canada) and standing height was measured using a wall stadiometer (Perspective Enterprises, Portage, MI, USA). Lean body mass and total adiposity were measured by DXA (General Electric Lunar Corporation version 6.10.019, Madison, WI, USA). Percent coefficient of variation was $0.8 \%$ for lean body mass and $1.1 \%$ for total adiposity.

\section{Computed tomography (CT)}

A GE High Speed Advantage CT scanner (General Electric Medical Systems, Milwaukee, WI, USA) was used to evaluate visceral and subcutaneous fat areas at the L4-L5 using a scout image of the body. Subjects were examined in the supine position with both arms stretched above their head. Visceral adipose tissue area was quantified by delineating the intra-abdominal cavity at the most internal aspect of the abdominal and oblique muscle walls surrounding the cavity and the posterior aspect of the vertebral body. Test-retest measures of the different body fat distribution compartments on ten CT scans yielded a mean absolute difference of $1 \%$ in obese postmenopausal women (25).

\section{Statistical analysis}

The data are expressed as mean \pm s.D. A repeated measures ANOVA was used to detect a significant effect of time within the EHC (0 vs 60, 160, 170, and $180 \mathrm{~min}$ ). If a significant time interaction was observed, a Bonferroni test was used to identify the differences between fasting and other values throughout the clamp. Insulin-induced AcylG and TotG maximal reductions were evaluated for each subject using the fasting value (0 min) minus the lowest value during the hyperinsulinemic state. Area under the curve values (AUC) were assessed to provide an overall index of hormonal profiles throughout the EHC and were calculated by the trapezoidal method. The relationships of AcylG or TotG with CRP, TNF- $\alpha$, or sTNF-R1 were evaluated by Pearson's correlations. Partial correlation analyses were evaluated in order to correct for the effect of total adiposity. Statistical analyses were performed with SPSS for Windows version 11.5 (SPSS Inc., Chicago, IL, USA). Significance was accepted at $P<0.05$.

\section{Results}

Fifty-three overweight and obese postmenopausal women were enrolled in this study. These women displayed a broad range of body weights, body composition, blood lipid, insulin resistance, and inflammatory profiles as presented in Tables 1 and 2. One month before testing, weight stability (within $\pm 1 \mathrm{~kg}$ ) was verified by monitoring body weight for each subject on a weekly basis. Due to this weight stabilization period, two subjects displayed a BMI slightly under $27 \mathrm{~kg} / \mathrm{m}^{2}$ on testing day and were therefore excluded from statistical analyses. The average BMI of this population was $32.8 \pm 4.2 \mathrm{~kg} / \mathrm{m}^{2}$ with 16 overweight (average: $28.6 \pm 0.9 \mathrm{~kg} / \mathrm{m}^{2}$ ) and 32 obese (average: $34.9 \pm 3.6 \mathrm{~kg} / \mathrm{m}^{2}$ ) individuals. Three subjects displayed supra-physiological levels of either CRP or sTNF-R1 and were not taken into consideration for statistical analyses.

CRP and sTNF-R1 levels were positively associated with total adiposity $(r=0.41, P=0.004$ and $r=0.44$, $P=0.002$ respectively), subcutaneous adipose tissue ( $r=0.42, P=0.003$ and $r=0.43, P=0.003$ respectively), and visceral adiposity $(r=0.54, P<0.001$ and $r=0.39$, $P=0.006$ respectively). On the other hand, AcylG profiles were significantly correlated with total adiposity $(r=-0.35, P=0.02)$ but not with subcutaneous

Table 1 Physical characteristics of 48 overweight and obese postmenopausal women.

\begin{tabular}{lcc}
\hline Physical characteristics & Mean \pm s.D. & Range \\
\hline Age (years) & $58.0 \pm 5.8$ & $48.8-72.9$ \\
Height $(\mathrm{m})$ & $1.60 \pm 0.06$ & $1.50-1.73$ \\
Body mass $(\mathrm{kg})$ & $84.1 \pm 13.8$ & $62.6-123.6$ \\
BMI $\left(\mathrm{kg} / \mathrm{m}^{2}\right)$ & $32.8 \pm 4.2$ & $27.0-42.8$ \\
Total adiposity $(\mathrm{kg})$ & $39.14 \pm 8.8$ & $25.2-61.2$ \\
Lean body mass $(\mathrm{kg})$ & $42.57 \pm 6.9$ & $32.6-61.3$ \\
Percent body fat $(\%)$ & $46.3 \pm 4.7$ & $37.4-56.9$ \\
Subcutaneous adipose tissue $\left(\mathrm{cm}^{2}\right)$ & $480 \pm 125$ & $289-776$ \\
Visceral adipose tissue $\left(\mathrm{cm}^{2}\right)$ & $191 \pm 61.8$ & $93.7-345.6$
\end{tabular}

Values are the mean \pm s.D. BMI, body mass index; total adiposity and fat-free mass were measured by dual energy X-ray absorptiometry. 
Table 2 Metabolic and inflammatory profile characteristics of 48 overweight and obese postmenopausal women.

\begin{tabular}{lcc}
\hline Variable & Mean \pm s.D. & Range \\
\hline Total cholesterol $(\mathrm{mmol} / \mathrm{l})$ & $5.72 \pm 0.82$ & $4.01-7.45$ \\
Triglycerides $(\mathrm{mmol} / \mathrm{l})$ & $1.77 \pm 0.76$ & $0.7-4.5$ \\
$\mathrm{HDL}-$-cholesterol $(\mathrm{mmol} / \mathrm{l})$ & $1.51 \pm 0.32$ & $0.99-2.36$ \\
LDL-cholesterol $(\mathrm{mmol} / \mathrm{l})$ & $3.40 \pm 0.75$ & $1.43-5.09$ \\
Fasting glucose $(\mathrm{mmol} / \mathrm{l})$ & $4.99 \pm 0.44$ & $4.00-5.83$ \\
Fasting insulin $(\mu \mathrm{U} / \mathrm{ml})$ & $15.22 \pm 7.11$ & $4.87-44.48$ \\
HOMA-IR & $3.40 \pm 1.68$ & $1.00-9.50$ \\
Insulin sensitivity $(\mathrm{mg} / \mathrm{min}$ per & $11.76 \pm 3.55$ & $4.76-19.04$ \\
$\quad \mathrm{~kg}$ FFM) & & \\
Fasting CRP $(\mathrm{mg} / \mathrm{l})$ & $3.98 \pm 3.43(n=47)$ & $0.40-14.60$ \\
Fasting TNF- $\alpha(\mathrm{pg} / \mathrm{ml})$ & $0.68 \pm 0.63(n=46)$ & $0.40-14.60$ \\
Fasting sTNF-R1 $(\mathrm{pg} / \mathrm{ml})$ & $995 \pm 209(n=47)$ & $612-1607$ \\
\end{tabular}

Values are mean \pm s.D. HDL-cholesterol, high density lipoprotein; LDLcholesterol, low density lipoprotein; HOMA-IR, homeostasis model assessment for insulin resistance; FFM, fat free mass; Mm value, insulin sensitivity at steady state; CRP, high sensitivity C-reactive protein; $\mathrm{TNF}-\alpha$, high sensitivity tumor necrosis factor $\alpha$; sTNF-R1, soluble tumor necrosis factor receptor 1 .

adiposity $(r=-0.26$; not significant $)$ nor visceral adiposity (AcylG: $r=-0.22$; not significant). Therefore, the different associations were adjusted for the effect of total adiposity. Meanwhile, sTNF-R1 concentrations were also positively associated with body weight, fasting insulinemia, and HOMA-IR $(r=0.39, P=0.007 ; r=0.44$, $P=0.002$ and $r=0.44, P=0.002$ respectively) but negatively associated with total and LDL-cholesterol ( $r=-0.31, P=0.04$ and $r=-0.41, P=0.005$ respectively). However, no significant interaction was observed with TNF- $\alpha$.

The relationships between ghrelin (acylated and total) and the inflammatory markers are presented in Table 3. In fasting conditions, sTNF-R1 was negatively linked with both fasting AcylG $(r=-0.48, P=0.001$; see Fig. 1) and AcylG/TotG $(r=-0.44, P=0.002)$. Following adjustments for total adiposity, sTNF-R1 remained significantly associated with both fasting AcylG $(r=-0.38, \quad P=0.009)$ and AcylG/TotG $(r=-0.32 ; P=0.03)$ values. TNF- $\alpha$ was positively correlated with Acylg/TotG ratio $(r=0.38, P=0.009)$

Table 3 Associations between ghrelin profiles and chronic inflammatory markers in overweight and obese postmenopausal women.

\begin{tabular}{llcc}
\hline & \multicolumn{3}{c}{ Pearson's correlations $(r)$} \\
\cline { 2 - 4 } & $\begin{array}{l}\text { CRP } \\
(n=47)\end{array}$ & $\begin{array}{l}\text { TNF- } \alpha \\
(n=46)\end{array}$ & $\begin{array}{l}\text { sTNF-R1 } \\
(n=47)\end{array}$ \\
\hline Fasting TotG & -0.21 & -0.07 & -0.14 \\
Fasting AcylG & -0.21 & 0.25 & $-0.48^{\dagger}$ \\
Fasting AcylG/TotG & -0.06 & $0.38^{\dagger}$ & $-0.44^{\dagger}$ \\
TotG AUC & -0.14 & -0.15 & -0.05 \\
AcylG AUC & -0.14 & 0.21 & $-0.34^{*}$ \\
AcylG/TotG AUC & -0.03 & $0.36^{\star}$ & $-0.29^{\star}$ \\
TotG maximal reduction & $-0.33^{\star}$ & 0.05 & -0.25 \\
AcylG maximal reduction & -0.19 & 0.11 & $-0.35^{\star}$ \\
\hline
\end{tabular}

TotG, total ghrelin; AUC, area under the curve; AcylG, acylated ghrelin; AcylG/TotG, acylated ghrelin over total ghrelin ratio. ${ }^{\star} P<0.05 ;{ }^{\dagger} P<0.01$.

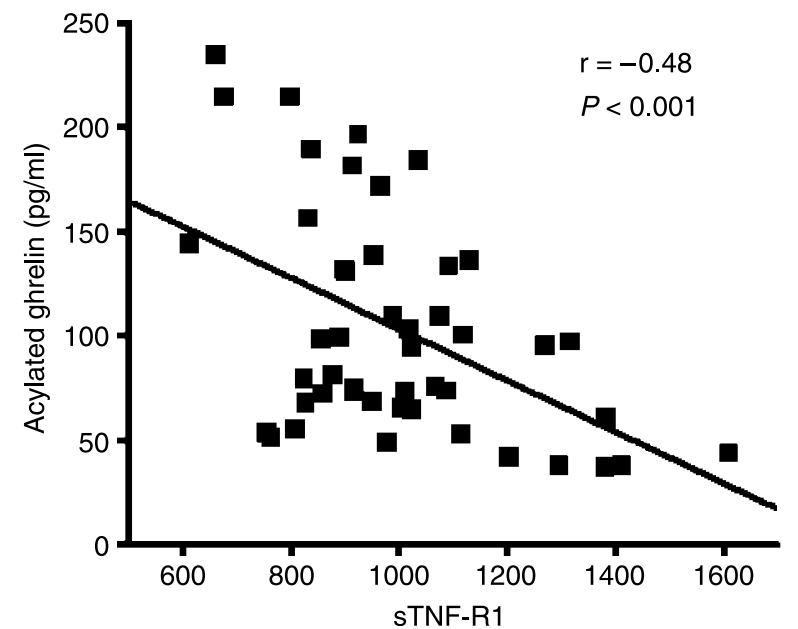

Figure 1 Correlation between fasting acylated ghrelin and sTNF-R1 levels. Open squares indicate overweight and obese postmenopausal women. The line of best fit is indicated. The partial $r$ value remained significant after statistical control for total adiposity.

and the association was still significant after correcting for total adiposity $(r=0.40, P=0.007)$. However, no significant relationship was observed between CRP and AcylG or AcylG/TotG.

The effect of a prolonged hyperinsulinemic state on ghrelin (acylated and total) circulating levels is described in Fig. 2. When compared with baseline, AcylG, and TotG concentrations were reduced throughout the EHC, while the AcylG/TotG ratio remained
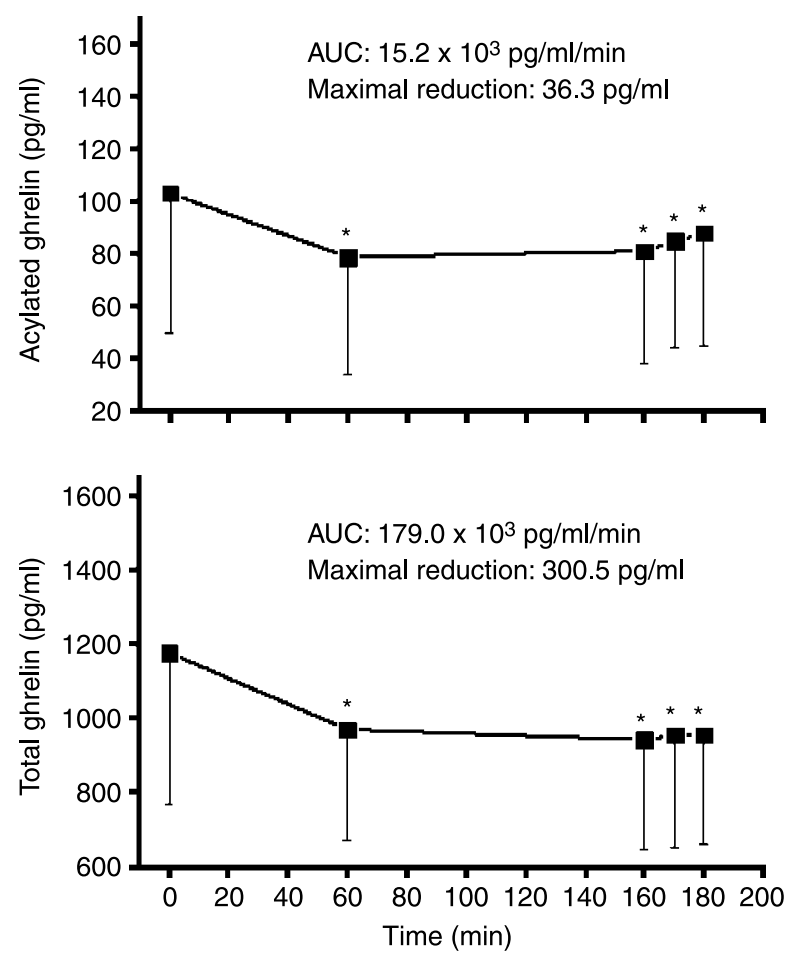

Figure 2 Acylated and total ghrelin circulation profile throughout $\mathrm{EHC}$ in overweight and obese postmenopausal women. Values are means \pm S.D. *Significantly different from fasting values $(P<0.05)$. 
Table 4 Independent predictors of soluble tumor necrosis factor receptor 1 (sTNF-R1) in overweight and obese postmenopausal women.

\begin{tabular}{lclcccc}
\hline Dependent variable & Step & Independent variables & Relationship & Partial $\boldsymbol{r}^{\mathbf{2}}$ & Total $\boldsymbol{r}^{\mathbf{2}}$ cumulative & $\boldsymbol{P}$ value \\
\hline sTNF-R1 $^{\text {a }}$ & 1 & Fasting AcylG & - & 0.23 & 0.23 & 0.001 \\
& 2 & LDL-cholesterol & - & 0.15 & 0.38 & 0.002 \\
& 3 & Fasting insulin & + & 0.09 & 0.47 & 0.01 \\
\hline
\end{tabular}

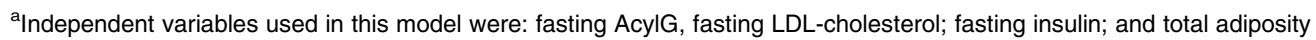

constant in fasting $(0.09 \pm 0.04)$ and EHC-induced $(0.09 \pm 0.05)$ conditions.

Maximal reduction of TotG and AcylG levels was observed between 60 and 180 min of the EHC. Insulinstimulated maximal reduction of TotG and AcylG values were negatively linked to CRP $(r=-0.33, P=0.03)$ and sTNF-R $1(r=-0.35, P=0.02)$ respectively. After controlling for the effect of total adiposity, only insulinstimulated maximal reduction of AcylG remained negatively linked to sTNF-R1 $(r=-0.31, P=0.04)$. We also observed that sTNF-R1 was associated with AUC values of AcylG $(r=-0.34, P=0.02)$ and the AcylG/Total ratio $(r=-0.34, P=0.02)$, but these associations did not remain significant after correcting for total adiposity $(P>0.05)$. Finally, TNF- $\alpha$ was correlated with AcylG/TotG AUC $(r=0.36, P=0.02)$ and the association persisted after correcting for total adiposity $(r=0.37, P=0.01)$.

As presented in Table 4, a stepwise regression analysis showed that fasting levels of AcylG, LDLcholesterol, and insulinemia explained 47\% (23, 15, and $9 \%$ respectively) of the variation in STNF-R 1 levels. On the other hand, neither AcylG nor TotG were independent predictors of CRP and TNF- $\alpha$ (data not shown).

\section{Discussion}

There is growing evidence suggesting the existence of a relationship between GI tract-derived hormones and chronic inflammatory markers, which may contribute to the development of obesity-related disturbances such as insulin resistance and type 2 diabetes (17). Recent studies have provided conflicting information regarding interactions of fasting TotG with CRP and TNF- $\alpha$ in patients with different chronic diseases $(20,21)$. However, these relationships were never evaluated in a model of obesity. Previous investigations have indicated that fasting levels of CRP, TNF- $\alpha$, and sTNFR1 are not significantly modulated during the EHC (26-31). Therefore, in the present study, CRP, TNF- $\alpha$, and sTNF-R 1 concentrations were only evaluated in a fasted state. On the other hand, our group and several others have reported that the amplitude of ghrelin reduction during postprandial and hyperinsulinemic states is representative of the metabolic status $(8,9,32$, 33). Therefore, the present study provides novel information regarding associations between chronic inflammatory markers and complete EHC-induced ghrelin (AcylG and TotG) profiles in a model of overweight and obese individuals characterized by a broad range of body composition and insulin sensitivity.

To our knowledge, the relationships between ghrelin profiles and markers of chronic inflammation were not evaluated in any other study involving overweight and obese individuals with increased risks of developing insulin resistance. Moreover, the present results indicate that under fasting and EHC-induced conditions, AcylG profiles were negatively associated with sTNF-R1 concentrations while AcylG/TotG ratios (fasting and AUC) were positively correlated with TNF- $\alpha$ levels. These interactions persisted after controlling for the effect of total adiposity. Moreover, fasting AcylG independently predicted $23 \%$ of the variation in sTNF$\mathrm{R} 1$ concentrations.

In this study, elevated AcylG/TotG values are associated with increased TNF- $\alpha$ concentration. This is in line with recent observations by our group and others suggesting that increased AcylG concentrations/proportions are associated with a detrimental metabolic profile. $(8,12,13)$. The TNF- $\alpha$ system (including TNF- $\alpha$, its soluble receptors sTNF-R1 and sTNF-R2) is recognized as an inflammatory component for the development of metabolic disturbances in overweight subjects (34-36). Moreover, recent advances suggest that TNF- $\alpha$ increases insulin resistance in skeletal muscle, hepatocytes, and adipose tissues by decreasing the expression of glucose transporter-4 and insulin receptor substrate-2 (3739). Previous authors have reported that fasting AcylG levels are negatively correlated with circulating TNF- $\alpha$ concentrations in women with gestational diabetes mellitus and TotG in patients with chronic pulmonary diseases $(20,40)$. In contrast, a positive association was observed between fasting TotG and TNF- $\alpha$ concentrations in patients with bowel disease, postoperational abdominal sepsis, or chronic heart failure $(21,41,42)$. However, because of its autocrine effects (43), blood samples may not be representative of localized TNF- $\alpha$ levels/activities in specific organs or tissues. Therefore, it could be relevant to evaluate individual and combined effects of ghrelin and TNF- $\alpha$ in isolated tissues (i.e., adipose and skeletal muscle tissues) collected from animal models with metabolic abnormalities. Moreover, the present results suggest that the existence of a relationship between AcylG/ TotG and TNF- $\alpha$ in overweight and obese 
postmenopausal women, this association could be further investigated in larger populations with specific metabolic disturbances (such as different levels of insulin sensitivity). In turn, these studies could provide novel information regarding the physiological implications of ghrelin and TNF- $\alpha$ in chronic inflammatory states.

To our knowledge, interactions between ghrelin and sTNF-R1 were never reported in any other study. As previously suggested sTNF-R 1 binds to TNF- $\alpha$ and therefore prevents the sustained immune priming resulting from the activation of the functional membrane-bound TNF-R1 $(44,45)$. In humans and rats, it was previously observed that weight loss suppresses sTNF-R1 levels but not TNF- $\alpha$ concentrations (46-48). Moreover, the amplitude of sTNF-R1 reduction is an independent predictor of insulin sensitivity improvements after weight loss (47). Thus, sTNF-R1 may be a better predictor of insulin resistance and metabolic dysfunctions than TNF- $\alpha$ (16). Our results indicate that AcylG levels are negatively associated with and are independent predictors of sTNF-R 1 concentrations in overweight and obese postmenopausal women. Furthermore, AcylG/TotG ratios are positively associated with TNF- $\alpha$. The present observations suggest that AcylG could be a two-way mediator of TNF- $\alpha$ system activation. Consequently, higher AcylG concentrations/proportions may play a dual role on potentiating TNF- $\alpha$ system activity, and could therefore increase the incidence of obesity-related disturbances in overweight and obese postmenopausal women.

We observed that insulin-induced maximal reduction of TotG levels was negatively correlated with fasting levels of CRP. Similar results were obtained by Luo et al., in patients suffering from chronic obstructive pulmonary disease (20). However, this association did not remain significant after controlling for total adiposity. Numerous groups have reported that the development of metabolic dysfunctions is closely associated with deleterious ghrelin profiles $(10,49)$ and with elevated fasting CRP levels (50-55). Thus, the present results suggest that decreased EHC-stimulated reduction of ghrelin levels are associated with elevated CRP concentrations in a population highly susceptible to develop obesity-related disturbances.

The current study is limited by several factors. First, our cohort is composed of overweight and obese sedentary postmenopausal women who display a wide range of severity in their metabolic phenotypes. Therefore, our findings were limited to this population. Secondly, we used a cross-sectional approach, which does not allow us to make conclusions on any causal associations between the inflammatory state and the hormonal profile in our cohort. Despite these limitations, our results are strengthened by the use of gold standard techniques for the evaluation of various metabolic risk factors in a relatively large wellcharacterized cohort.
In conclusion, the present results provide new evidence of the association between AcylG profiles and inflammatory markers, more specifically the TNF- $\alpha$ system, in a population of overweight and obese postmenopausal women. Further investigations will be needed to elucidate the mechanisms underlying the regulation of AcylG, TNF- $\alpha$, and sTNF-R1 in normal subjects and in patients suffering from obesity-related complications. Ultimately, a better understanding of the relationship between ghrelin and the TNF- $\alpha$ system may lead to new clinical targets for the development of novel therapies against metabolic disturbances.

\section{Acknowledgements}

David H St-Pierre is funded by Canadian Institutes of Health Research (CIHR) doctoral fellowship. Rémi Rabasa-Lhoret and Martin Brochu hold Fond de Recherche en Santé du Québec (FRSQ) research scholar grants. Katherine Cianflone holds a Canada Research Chair in Adipose Tissue. Eric Doucet is a recipient of a CIHR/Merck-Frosst New Investigator Award and CFI/OIT New Opportunities Award. This study was supported by grants from the CHIR New Emerging Teams in Obesity (Université de Montréal and University of Ottawa; MONET project) and from the CIHR Operating Grant. We would like to thank Mrs Lyne Messier for the coordination of this study. We would also like to acknowledge Dr Huy Ong and the members of laboratory for their technical and scientific input. We would like to thank Dr Miguel Chagnon for his precious counseling for statistical analyses. We thank BeckmanCoulter, France for the kind gift of antibodies to perform all of the protein measurements. Finally, we thank Doctor Fellahi for her participation on inflammatory markers analysis.

\section{References}

1 Kojima M, Hosoda $H$, Date $Y$, Nakazato M, Matsuo H \& Kangawa K. Ghrelin is a growth-hormone-releasing acylated peptide from stomach. Nature $1999 \mathbf{4 0 2} 656-660$.

2 Kojima M \& Kangawa K. Ghrelin: structure and function. Physiological Reviews $2005 \mathbf{8 5}$ 495-522.

3 Williams DL \& Cummings DE. Regulation of ghrelin in physiologic and pathophysiologic states. Journal of Nutrition $20051351320-1325$.

4 Popovic V \& Duntas LH. Leptin TRH and ghrelin: influence on energy homeostasis at rest and during exercise. Hormone Metabolic Research 200537 533-537.

5 St-Pierre DH, Wang L \& Tache Y. Ghrelin: a novel player in the gut-brain regulation of growth hormone and energy balance. News in Physiological Sciences 200318 242-246.

6 Ghigo E, Broglio F, Arvat E, Maccario M, Papotti M \& Muccioli G. Ghrelin: more than a natural GH secretagogue and/or an orexigenic factor. Clinical Endocrinology 200562 1-17.

7 Patterson M, Murphy KG, le Roux CW, Ghatei MA \& Bloom SR. Characterization of ghrelin-like immunoreactivity in human plasma. Journal of Clinical Endocrinology and Metabolism 200590 2205-2211. 
8 St-Pierre DH, Karelis AD, Coderre L, Malita F, Fontaine J, Mignault D, Brochu M, Bastard JP, Cianflone K, Doucet E, Imbeault P \& Rabasa-Lhoret R. Association of acylated and nonacylated ghrelin with insulin sensitivity in overweight and obese postmenopausal women. Journal of Clinical Endocrinology and Metabolism 200792 264-269.

9 le Roux CW, Patterson M, Vincent RP, Hunt C, Ghatei MA \& Bloom SR. Postprandial plasma ghrelin is suppressed proportional to meal calorie content in normal-weight but not obese subjects. Journal of Clinical Endocrinology and Metabolism $2005901068-1071$.

10 Anderwald C, Brabant G, Bernroider E, Horn R, Brehm A, Waldhausl W \& Roden M. Insulin-dependent modulation of plasma ghrelin and leptin concentrations is less pronounced in type 2 diabetic patients. Diabetes 200352 1792-1798.

11 Paik KH, Choe YH, Park WH, Oh YJ, Kim AH, Chu SH, Kim SW, Kwon EK, Han SJ, Shon WY \& Jin DK. Suppression of acylated ghrelin during oral glucose tolerance test is correlated with whole-body insulin sensitivity in children with Prader-Willi syndrome. Journal of Clinical Endocrinology and Metabolism 200691 1876-1881.

12 Gauna C, Delhanty PJ, Hofland LJ, Janssen JA, Broglio F, Ross RJ, Ghigo E \& van der Lely AJ. Ghrelin stimulates, whereas des-octanoyl ghrelin inhibits, glucose output by primary hepatocytes. Journal of Clinical Endocrinology and Metabolism 200590 1055-1060.

13 Gauna C, Meyler FM, Janssen JA, Delhanty PJ, Abribat T, van Koetsveld P, Hofland LJ, Broglio F, Ghigo E \& van der Lely AJ. Administration of acylated ghrelin reduces insulin sensitivity, whereas the combination of acylated plus unacylated ghrelin strongly improves insulin sensitivity. Journal of Clinical Endocrinology and Metabolism $2004 \mathbf{8 9}$ 5035-5042.

14 Behre CJ, Fagerberg B, Hulten LM \& Hulthe J. The reciprocal association of adipocytokines with insulin resistance and C-reactive protein in clinically healthy men. Metabolism 2005 54 439-444.

15 Corica F, Allegra A, Corsonello A, Buemi M, Calapai G, Ruello A, Nicita Mauro V \& Ceruso D. Relationship between plasma leptin levels and the tumor necrosis factor-alpha system in obese subjects. International Journal of Obesity and Related Metabolic Disorders 199923 355-360.

16 Vigouroux C, Maachi M, Nguyen TH, Coussieu C, Gharakhanian S, Funahashi T, Matsuzawa Y, Shimomura I, Rozenbaum W, Capeau J \& Bastard JP. Serum adipocytokines are related to lipodystrophy and metabolic disorders in HIV-infected men under antiretroviral therapy. AIDS $2003 \mathbf{1 7} 1503-1511$.

17 Dixit VD \& Taub DD. Ghrelin and immunity: a young player in an old field. Experimental Gerontology 200540 900-910.

18 Li WG, Gavrila D, Liu X, Wang L, Gunnlaugsson S, Stoll LL, McCormick ML, Sigmund CD, Tang C \& Weintraub NL. Ghrelin inhibits proinflammatory responses and nuclear factor- $\kappa \mathrm{B}$ activation in human endothelial cells. Circulation $20041092221-2226$.

19 Dixit VD, Schaffer EM, Pyle RS, Collins GD, Sakthivel SK, Palaniappan R, Lillard JW, Jr \& Taub DD. Ghrelin inhibits leptinand activation-induced proinflammatory cytokine expression by human monocytes and T cells. Journal of Clinical Investigation 2004 $11457-66$.

20 Luo FM, Liu XJ, Li SQ, Wang ZL, Liu CT \& Yuan YM. Circulating ghrelin in patients with chronic obstructive pulmonary disease. Nutrition 200521 793-798.

21 Nagaya N, Uematsu M, Kojima M, Date Y, Nakazato M, Okumura H, Hosoda H, Shimizu W, Yamagishi M, Oya H, Koh H, Yutani C \& Kangawa K. Elevated circulating level of ghrelin in cachexia associated with chronic heart failure: relationships between ghrelin and anabolic/catabolic factors. Circulation $2001 \mathbf{1 0 4} 2034-2038$.

22 DeFronzo RA, Tobin JD \& Andres R. Glucose clamp technique: a method for quantifying insulin secretion and resistance. American Journal of Physiology 1979237 E214-E223.
23 Friedewald WT, Levy RI \& Fredrickson DS. Estimation of the concentration of low-density lipoprotein cholesterol in plasma, without use of the preparative ultracentrifuge. Clinical Chemistry 197218 499-502.

24 Matthews DR, Hosker JP, Rudenski AS, Naylor BA, Treacher DF \& Turner RC. Homeostasis model assessment: insulin resistance and beta-cell function from fasting plasma glucose and insulin concentrations in man. Diabetologia $19852 \mathbf{2 8} 412-419$.

25 Brochu M, Tchernof A, Dionne IJ, Sites CK, Eltabbakh GH, Sims EA \& Poehlman ET. What are the physical characteristics associated with a normal metabolic profile despite a high level of obesity in postmenopausal women? Journal of Clinical Endocrinology and Metabolism 200186 1020-1025.

26 Charuruks N, Laohajinda B, Rujiwanitgun S \& Chaiworaporn M. Reference value for C-reactive protein and its distribution pattern in Thai adults. Circulation Journal 200569 339-344.

27 Meier-Ewert HK, Ridker PM, Rifai N, Price N, Dinges DF \& Mullington JM. Absence of diurnal variation of C-reactive protein concentrations in healthy human subjects. Clinical Chemistry $200147426-430$.

28 Johansson A, Ahren B, Forsberg H \& Olsson T. Testosterone and diurnal rhythmicity of leptin, TNF- $\alpha$ and TNF-II receptor in insulin-resistant myotonic dystrophy patients. International Journal of Obesity and Related Metabolic Disorders 200226 1386-1392.

29 Jellema A, Plat J \& Mensink RP. Weight reduction, but not a moderate intake of fish oil, lowers concentrations of inflammatory markers and PAI-1 antigen in obese men during the fasting and postprandial state. European Journal of Clinical Investigation 2004 $34766-773$.

30 Twickler TB, Dallinga-Thie GM, Visseren FL, de Vries WR, Erkelens DW \& Koppeschaar HP. Induction of postprandial inflammatory response in adult onset growth hormone deficiency is related to plasma remnant-like particle-cholesterol concentration. Journal of Clinical Endocrinology and Metabolism $2003 \mathbf{8 8}$ $1228-1233$

31 Nappo F, Esposito K, Cioffi M, Giugliano G, Molinari AM, Paolisso G, Marfella R \& Giugliano D. Postprandial endothelial activation in healthy subjects and in type 2 diabetic patients: role of fat and carbohydrate meals. Journal of the American College of Cardiology 200239 1145-1150.

32 Ikezaki A, Hosoda H, Ito K, Iwama S, Miura N, Matsuoka H, Kondo C, Kojima M, Kangawa K \& Sugihara S. Fasting plasma ghrelin levels are negatively correlated with insulin resistance and PAI-1, but not with leptin, in obese children and adolescents. Diabetes 200251 3408-3411.

33 Mohlig M, Spranger J. Otto B, Ristow M, Tschop M \& Pfeiffer AF. Euglycemic hyperinsulinemia, but not lipid infusion, decreases circulating ghrelin levels in humans. Journal of Endocrinological Investigation 200225 RC36-RC38.

34 Halle M, Berg A, Northoff H \& Keul J. Importance of TNF- $\alpha$ and leptin in obesity and insulin resistance: a hypothesis on the impact of physical exercise. Exercise Immunology Review 19984 77-94.

35 Winkler G, Lakatos P, Salamon F, Nagy Z, Speer G, Kovacs M, Harmos G, Dworak O \& Cseh K. Elevated serum TNF- $\alpha$ level as a link between endothelial dysfunction and insulin resistance in normotensive obese patients. Diabetic Medicine 199916 207-211.

36 Chu NF, Spiegelman D, Hotamisligil GS, Rifai N, Stampfer M \& Rimm EB. Plasma insulin, leptin, and soluble TNF receptors levels in relation to obesity-related atherogenic and thrombogenic cardiovascular disease risk factors among men. Atherosclerosis $2001157495-503$.

37 Hauner H, Petruschke T, Russ M, Rohrig K \& Eckel J. Effects of tumour necrosis factor alpha (TNF $\alpha$ ) on glucose transport and lipid metabolism of newly-differentiated human fat cells in cell culture. Diabetologia $1995 \mathbf{3 8} 764-771$.

38 Borst SE, Lee Y, Conover CF, Shek EW \& Bagby GJ. Neutralization of tumor necrosis factor-alpha reverses insulin resistance in skeletal muscle but not adipose tissue. American Journal of Physiology. Endocrinology and Metabolism 2004287 E934-E938. 
39 Wang Z, Lv J, Zhang R, Zhu Y, Zhu D, Sun Y, Zhu J \& Han X. Co-culture with fat cells induces cellular insulin resistance in primary hepatocytes. Biochemical and Biophysical Research Communications $20063 \mathbf{3 4 5} 976-983$.

40 Palik E, Baranyi E, Melczer Z, Audikovszky M, Szocs A, Winkler G \& Cseh K. Elevated serum acylated (biologically active) ghrelin and resistin levels associate with pregnancy-induced weight gain and insulin resistance. Diabetes Research and Clinical Practice 200776 351-357.

41 Maruna P, Gurlich R, Frasko R \& Rosicka M. Ghrelin and leptin elevation in postoperative intra-abdominal sepsis. European Surgical Research 200537 354-359.

42 Peracchi M, Bardella MT, Caprioli F, Massironi S, Conte D, Valenti L, Ronchi C, Beck-Peccoz P, Arosio M \& Piodi L. Circulating ghrelin levels in patients with inflammatory bowel disease. Gut 2006 55 432-433.

43 Hotamisligil GS, Shargill NS \& Spiegelman BM. Adipose expression of tumor necrosis factor-alpha: direct role in obesity-linked insulin resistance. Science 1993259 87-91.

44 Bemelmans MH, van Tits LJ \& Buurman WA. Tumor necrosis factor: function, release and clearance. Critical Reviews in Immunology $1996 \mathbf{1 6} 1-11$.

45 Pennica D, Kohr WJ, Fendly BM, Shire SJ, Raab HE, Borchardt PE, Lewis M \& Goeddel DV. Characterization of a recombinant extracellular domain of the type 1 tumor necrosis factor receptor: evidence for tumor necrosis factor-alpha induced receptor aggregation. Biochemistry 199231 1134-1141.

46 Raina N, Lamarre J, Liew CC, Lofti AH \& Jeejeebhoy KN. Effect of nutrition on tumor necrosis factor receptors in weightgaining and -losing rats. American Journal of Physiology 1999 277 E464-E473.

47 Ryan AS \& Nicklas BJ. Reductions in plasma cytokine levels with weight loss improve insulin sensitivity in overweight and obese postmenopausal women. Diabetes Care 200427 1699-1705.

48 Bastard JP, Jardel C, Bruckert E, Vidal H \& Hainque B. Variations in plasma soluble tumour necrosis factor receptors after diet-induced weight loss in obesity. Diabetes, Obesity and Metabolism 20002 323-325.
49 Tschop M, Weyer C, Tataranni PA, Devanarayan V, Ravussin E \& Heiman ML. Circulating ghrelin levels are decreased in human obesity. Diabetes $20015 \mathbf{5 0} 707-709$.

50 Ridker PM, Buring JE, Cook NR \& Rifai N. C-reactive protein, the metabolic syndrome, and risk of incident cardiovascular events: an 8-year follow-up of 14719 initially healthy American women. Circulation 2003107 391-397.

51 Tracy RP, Lemaitre RN, Psaty BM, Ives DG, Evans RW, Cushman M, Meilahn EN \& Kuller LH. Relationship of C-reactive protein to risk of cardiovascular disease in the elderly. Results from the Cardiovascular Health Study and the Rural Health Promotion Project. Arteriosclerosis, Thrombosis, and Vascular Biology 199717 1121-1127.

52 Koenig W, Sund M, Frohlich M, Fischer HG, Lowel H, Doring A, Hutchinson WL \& Pepys MB. C-Reactive protein, a sensitive marker of inflammation, predicts future risk of coronary heart disease in initially healthy middle-aged men: results from the MONICA (Monitoring Trends and Determinants in Cardiovascular Disease) Augsburg Cohort Study, 1984 to 1992. Circulation 1999 99 237-242.

53 Danesh J, Whincup P, Walker M, Lennon L, Thomson A, Appleby P, Gallimore JR \& Pepys MB. Low grade inflammation and coronary heart disease: prospective study and updated meta-analyses. BMJ 2000321 199-204.

54 Pradhan AD, Manson JE, Rifai N, Buring JE \& Ridker PM. C-reactive protein, interleukin 6 , and risk of developing type 2 diabetes mellitus. JAMA 2001286 327-334.

55 Freeman DJ, Norrie J, Caslake MJ, Gaw A, Ford I, Lowe GD, O'Reilly DS, Packard CJ \& Sattar N. C-reactive protein is an independent predictor of risk for the development of diabetes in the West of Scotland Coronary Prevention Study. Diabetes 200251 1596-1600.

Received 23 January 2007

Accepted 12 July 2007 